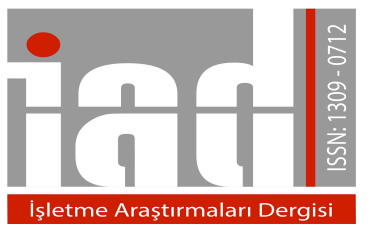

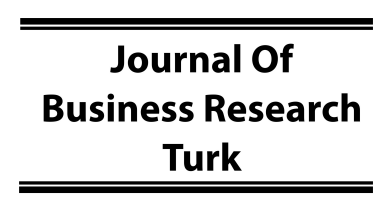

www.isarder.org

\title{
Veri Zarflama Analizi ile Türk Sigorta Sektörünün Elementer Branşlarda Değerlendirilmesi \\ Evaluation of Turkish Insurance Sector in Non-Life Insurance With Data Envelopment Analysis
}

\author{
Seher A. Tezergil \\ Marmara Üniversitesi \\ Bankacılık ve Sigortacılık Yüksekokulu \\ Aktüerya Bölümü, İstanbul, Türkiye \\ orcid.org/0000-0002-0228-724X \\ stezergil@marmara.edu.tr
}

\begin{abstract}
Özet
Bu çalışma Türk Sigorta Sektöründe son üç yıl için elementer branşlarda yer alan sigorta şirketlerine ait etkinlik düzeylerinin Veri Zarflama Analizi (VZA) ile belirlenmesi amaçlanmaktadır. VZA, parametrik olmayan bir etkinlik ölçüm yöntemidir. Veri Zarflama Analizi, benzer girdiler ile çıktı ya da çıktılar ortaya koyan karar birimlerinin göreceli etkinliklerini değerlendirmek için kullanılan ve doğrusal programlama tabanlı bir yöntem olarak tanımlanmaktadır. Çalışmada literatür değerlendirmesi ile belirlenmiş olan finansal ve finansal olmayan değişkenler kullanılmıştır. Kurulan model DEA-SOLVER programı ile çözülmüş olup, ölçeğe göre değişken getiri varsayımına dayanan Girdi Yönlü BBC Süper Etkinlik (SuperRadial(Super-BCC-I)) modeli kullanılmıştır.
\end{abstract}

Anahtar Kelimeler: Türk Sigorta Sektörü, Performans Değerlendirme, Veri Zarflama Analizi, Çok Amaçlı Karar Alma, Hayat Dışı Sigortacılık.

\section{Abstract}

This study is aimed to determine the efficiency levels of the insurance companies in elementary branches in the last three years period in the Turkish Insurance Sector with Data Envelopment Analysis (DEA). DEA is a nonparametric efficiency measurement method. Data Envelopment Analysis is defined as a linear programming based method used to evaluate the relative activities of decision units that produce outputs with similar inputs. Financial and non-financial variables determined by literature review were used in the study. The established model which is based on a variable return-based assumption, Banker-Charnes-Cooper (BCC) model was solved by the DEA-SOLVER program.

Keywords: Turkish Insurance Sector, Performance Evaluation, Data Envolopment Analysis, Multi-Criteria Decision-Making Analysis, Non-life Insurance. 


\section{Giriş}

Küreselleşen dünyada genelde hemen hemen her sektörde özelde ise ülke ekonomilerinde belirleyici olan finansal piyasalarda yaşanan rekabet sektör paydaşlarını kaynaklarını en etkin şekilde kullanmaya zorlamaktadır. Ülkemiz finansal piyasalarında da gelecek vadeden sektörlerinden birisi olan sigorta sektörünün rekabet ettikleri pazarda performanslarını göreli olarak değerlendirmesi ve etkinlik sınırlarında yer almak için referans almaları gereken şirketleri/rakipleri belirlemesi ileriye dönük stratejiler üretmede ve risklerini yönetmede son derece önem arz etmektedir. Söz konusu performans değerlemesinde sıklıkla karlılık, büyüme oranları, etkinlik ve verimlilik gibi kriterler kullanılmaktadır. Bu kriterlerden verimlilik; bir sistemin çıktılarının, bu çıktıyı elde etmek için kullandığı girdilere oranı şeklinde tanımlanırken, etkinlik ise maksimum çıktıyı en az kaynak kullanımı(girdi) ile elde edebilme gücü olarak tanımlanmakta olup dolayısıyla bu iki önemli kavram arasındaki ilişki; "verimlilik işi doğru yapmak, etkinlik ise doğru işi yapmak" şeklinde özetlenmektedir (Koçak ve Çilingirtürk,2011, ss.166-175).

$\mathrm{Bu}$ yaklaşım ekseninde şirketlerin etkinliklerinin analizi en az verimliliklerinin analizi kadar önem arz etmektedir. Çalışmada da söz konusu yaklaşım merkeze konularak Türk Sigorta Sektöründe son üç yıllık periyotta elementer branşlarda yer alan sigorta şirketlerine ait etkinlik düzeylerinin Veri Zarflama Analizi (VZA) ile belirlenmesi hedeflenmiştir. $\mathrm{Bu}$ değerlendirmenin rekabet gücü yüksek bir ekonomi yaratmada katkı sağlayacak yaklaşımlar üretmesi beklenmektedir.

\section{Literatür}

Literatürde VZA'nın teori ve uygulama alanlarında kullanımının yanı sıra bu kullanımları ile ilgili bibliyometrik çalışmaların da oldukça yaygın olduğu görülmektedir. Liu ve diğerleri (2013), 1978-2010 yılları arsında VZA ile ilgili çalışmaları teorik ya da ampirik olmasına bakmaksızın incelemişler ve çalışmaların üçte ikisini ampirik kalanının ise teorik çalışmalar olduğunu ifade etmişlerdir. Emrouznejad ve Yang (2017) çalışmalarında 1978-2016 yılları arasında VZA ile ilgili çalışmaların sayısının yıllarla beraber arttığı ve bu 40 yıl içerisinde literatürde toplam 10.300 adet makalenin yayınlandığını göstermişlerdir. Yayınlanan makalelerin ise özellikle 2004 yılından günümüze uzanan kısmında üstel bir artış sergilediği sonucuna ulaşmışlardır.

VZA modellerinin literatürde ilk kullanıldı̆̆ı tarihten bugüne hâlâ ilgi görüyor olmasının en temel sebebi doğrusal form dışında girdi ve çıktıları ilişkilendiren bir fonksiyonel forma ihtiyaç duymadan çok sayıda değişkenle etkinlik ölçümü yapmaya imkân tanıyor olmasıdır. Bu yöntemle enerji, eğitim, reklam gibi çok çeşitli sektörlerde çalışmalar yapıldığı bilinmesine karşın bu araştırmanın sigorta sektöründe olması sebebiyle finansal piyasalarda VZA yönteminin kullanıldığı çalışmalar araştırılarak bazıları aşağıda sıralanmıştır.

Mahlberg ve Url (2003) 1992-1994 yılları arasında Avusturya'da faaliyet gösteren 52 hayat ve hayat dişı sigorta şirketinin etkinliğini VZA ile ölçmüştür.

Kılıçkaplan ve Karpat (2004) çalışmasında 1998-2002 yılları arasında her yıl farklı sayıda faaliyet gösteren sigorta şirketlerinin teknik, saf ve ölçek etkinliklerinin araştırmışlardır. 
Bülbül ve Akhisar (2005) çalışmalarında(1999-2003) döneminde Türk Sigorta Sektörü'nde hayat dışı branşlarda faaliyet gösteren sigorta şirketlerinin etkinlik ölçümü, çıktıya göre VZA modeli kullanılarak analiz etmişlerdir.

Girginer, Yalam ve Kaygısız (2007) çalışmalarında hayat ve hayat dışı olmak üzere sigortacılık sektöründeki şirketlerin performanslarını (VZA) ve Kümeleme Analizi kullanarak karşılaştırmışlardır. Girdi olarak hayat ve hayat dışı sigorta şirketlerinde farklı gruplarda oluşturulmuş finansal oranları ve çıtı olarak bilanço karı/varlık toplamı ve bilanço karı/özkaynaklar oranlarını kullanmışlardır.

Turgutlu, Kök ve Kasman (2007), 1990-2004 döneminde hayat-dışı alanlarda faaliyet gösteren Türk sigortacilık şirketlerinde teknik etkinliği incelemiş, geleneksel veri zarflama analizi ve son dönemde geliştirilen şans-kısıtlı veri zarflama analizini kullanılarak her iki yöntemin sonuçlarının tutarlılığı, Spearman sıra korelasyonu ve Mann-Whitney-Wilcoxon testi ile sınanmıştır.

Chen,Cook,Li ve Zhu (2009), 2001-2002 yılları arasında Tayvan'da faaliyet gösteren hayatdışı sigorta şirketlerinin; Luhnen (2009),1995-2006 yılları arasında Almanya'da hayat dışı branşlarda faaliyet gösteren sigorta şirketlerinin; Barros, Nektarios ve Assaf (2010) 1994-2003 yılları arasında Yunanistan'da faaliyet gösteren hayat ve hayat dişı sigorta şirketlerinin; Cummins, Weiss,Xie ve Zi (2010) ,1993-2006 yılları arasında Amerika'da faaliyet gösteren hayat sigorta şirketlerinin performans değerlendirmesini VZA ile yapmıştır.

Yao, Han ve Feng (2010), emek, özkaynaklar, ödeme ve yardım değişkenlerini girdi; toplam prim üretimi ve yatırım gelirini ise çıktı değişkeni olarak alarak 20002005 yılları arasında Çin'de faaliyet gösteren 22 hayat ve hayat dışı sigorta şirketininin performas analizini yapmıştır.

Köse (2010),2004-2008 yılları arasında hayat ve emeklilik branşlarında faaliyet gösteren 18 sigorta şirketinin performans değerlendirmelerini yapmıştır.

Altan (2010) çalışmasında hayat dışı branşında faaliyet gösteren 25 sigorta şirketinin 2005-2007 yılları için birbirlerine göre verimliliklerini değerlendirmiştir.

Özcan (2011) 2002-2009 yılları arasında hayat dışı branşında faaliyet gösteren sigorta şirketlerininin performans değerlendirmesini; acente sayısı, çalışan sayısı ve sabit varlıkları girdi değişkenler toplam primler, bilanço kârı ve teknik kârı ise ve çıktı değişkenler alarak yapmıştır.

Dalkılıç (2012) çalışmasında hayat dışı sigorta şirketlerinin 2008-2010 dönemi itibariyle etkinliklerini girdi yönelimli ölçeğe göre değişken getirili BCC modeli ve Malmquist toplam faktör verimlilik endeksi kullanarak ölçmüştür. Şirketlerin etkinliğinin 2009 yılında arttığını, 2010 yılında ise düşüş gösterdiği sonucuna ulaşmıştır. Çetintaş ve Biçen (2012) aynı şekilde 2008-2010 yılları arasında sigortacılık sektörünün hayat dışı branşlarda faaliyet gösteren şirketlerin teknik etkinlik düzeylerini araştırmışlardır.

Çiftçi (2013) Türk sigorta sektörünün sorunlarını ele almış ve bu incelemeyi yaparken sigorta şirketlerini hayat ve hayat dışı branşlardaki sigorta şirketleri şeklinde gruplandırarak değerlendirmiştir. 1998-2002 yılları arasında faaliyet gösteren 62 sigorta şirketine ait verilerin ortalamalarını kullanılmıştır. 


\section{Yöntem}

Veri Zarflama Analizi (Data Envolepment Analysis) ilk olarak 1957 y1lında Michael James Farrell tarafindan üretim tekniklerinin analizinde kullanılmış daha sonra ise 1978 yılında Abraham Charnes, William W. Cooper ve Edwardo Rhodes tarafindan etkinlik ölçümünde matematiksel olarak modellenerek geliştirilmiş Çok Amaçlı Karar Alma Yöntemlerinden biridir. Söz konusu yöntem girdiler ve çıktılar arasındaki karmaşı ilişkinin analizinde zorlanan diğer tekniklere göre çok daha az varsayım gerektirmesinden dolayı uygulamada büyük kolaylık sağlamaktadır (Cooper ve diğerleri, 1978).

Karar verme ünitelerinin etkinliğini hesaplayan VZA yöntemi ilk olarak araştırmacıların baş harflerinden oluşan CCR (Charnes-Cooper-Rhodes) modelleri ile literatürde yer almış sonrasında ise ölçeğe göre sabit getiri varsayımını temel alan bu yaklaşım ölçeğe göre değişken getiri varsayımı ile genişletilerek BBC (Banker-CharnesCooper) modelleri oluşturulmuştur. Sonrasında ise girdiye ve çıktıya odaklı olarak değerlendirme yapan CCR ve BCC modellerinin yanı sıra her iki çeşit odaklanmayı da beraber değerlendiren toplamsal model ortaya konmuştur. Özetle Veri Zarflama Analizinde temel olarak CCR (Charnes-Cooper-Rhodes) Yöntemi, BCC (BankerChaenes-Cooper) Yöntemi ve Toplamsal Yöntem olmak üzere 3 yaklaşım mevcuttur. Daha önce de ifade edildiği gibi VZA, birden çok ve farklı ölçeklerle ölçülmüş ya da farklı ölçü birimlerine sahip girdi ve çıktının karşılaştırma yapmayı zorlaştırdığı durumlarda, karar birimlerinin göreli performanslarını ölçmeyi amaçlayan doğrusal programlama tabanlı bir tekniktir. Yani karar verme birimlerinin göreli etkinliklerini ölçmek için kullanılan parametrik olmayan bir yaklaşımdır (Bülbül\&Akhisar,2005, ss.26-27). VZA'da bir karar biriminin göreli etkinliği, toplam ağırlıklı çıktıların toplam ağırlıklı girdilere oranı şeklinde tanımlanmakta ve teknik etkinlik olarak da adlandırılmaktadır. Teknik etkinliğin hesaplanmasında karşılaşılan en önemli sorun, birden fazla girdi ve/veya çıktıların olduğu durumlarda girdi ve çıktılara ağırlıkların nasıl verilmesi gerektiğidir. VZA, hiçbir ağırlığın negatif değer taşımaması, analize konu olan diğer karar birimlerine de uygulandığında hiçbir karar biriminin etkinliğinin birden fazla olmaması kısıtları altında her karar birimine girdi ve çıktılarını istediği gibi ağırlıklandırma şansı vermekte ve her karar biriminin girdi ve çıktı ağırlıklarını kendi etkinlik derecesini maksimize edecek şekilde seçeceğini varsaymaktadır (Altan,2010,s. 8)

Ayrıca VZA modelleri daha önce de ifade edildiği gibi; "girdiye yönelik" ve "çıktıya yönelik" olmak üzere iki yaklaşımı merkeze alarak çalışmaktadır. (Özden, 2008, ss.170) Her iki yaklaşım da temelde birbirlerine çok benzemekle birlikte girdiye yönelik VZA modelleri; belirli bir çıktı bileşimini en etkin şekilde üretebilmek amacıyla kullanılacak en uygun girdi bileşiminin nasıl olması gerektiğini araştırırken, çıktıya yönelik VZA modelleri belirli bir girdi bileşimi ile en fazla ne kadar çıktı bileşimi elde edilebileceğini araştırmaktadır (Bülbül\&Akhisar,2005, ss.26-27).

VZA yöntemlerinde CCR ve BCC etkinlik araştırmasında, etkin olan birimlere 1 etkinlik skorunu atarken, etkin olmayan birimlere girdi yönlü modellerde 1 'den küçük, çıktı yönlü modellerde ise l'den büyük bir etkinlik skoru atamaktadır (Koçak\&Çilingirtürk,2011, s.172).

Veri Zarflama Analizi parametrik olmayan bir yöntem olması sebebiyle doğrusal form dışında, girdi ve çıktıları ilişkilendiren bir fonksiyonel forma ihtiyaç duymaması, çok sayıdaki girdi ve çıktı karar verme birimlerinin etkinlik ölçümünde kullanılabilir 
olması, girdi ve çıktılar için farklı ölçeklendirmelerin kullanılabilir olması ve varsayıma ihtiyaç duyulmaması gibi birçok avantajı sebebiyle performans ölçümünde oldukça etkin bir araçtır.Bunun yanı sıra parametrik olmaması nedeniyle sonuçlara istatistiksel hipotez testlerinin uygulanmasındaki karmaşıklık, büyük boyutlu problemlerin VZA ile çözümünün hesaplamada çok zaman alması, elde edilen etkinlik skorlarının yalnızca incelenen gözlem kümesi için geçerli olması, farklı karar verme birimlerinin yer alacağı başka bir çalışmadan elde edilen etkinlik skorları ile karşılaştırma yapmanın olanaksızlığı gibi dezavantajları da söz konusudur. (Sarı,2015, ss.15,16)

Tutarlı ve doğru sonuçlara ulaşmak için yöntemin avantaj ve dezavantajları göz önünde bulundurulmalı ve daha sonra uygulama aşamalarına dikkat edilmelidir. VZA uygulama aşamaları,

- Karar verme birimlerinin seçilmesi,

- Girdi ve çıktı değişkenlerinin belirlenmesi,

- Uygun VZA modelinin seçilmesi,

- Etkinlik Değerlerinin Belirlenmesi

- Referans Kümelerinin Belirlenmesi,

- Etkin Olmayan Karar Verme Birimleri İçin Stratejilerin

belirlenmesişeklinde sıralanabilir. Uygulamada Girdi Yönlü BCC Süper Etkinlik (Super-Radial(Super-BCC-I)) modeli kullanılacağı için çalışmada sadece bu modele ilişkin genel formülasyon aşağıda verilmiştir:

\section{Girdi Yönlü BCC Modeli}

$$
\begin{aligned}
& E_{i}=\operatorname{Min} \alpha-\varepsilon\left(\sum_{i=1}^{1 n} s_{i}^{-}\right)-\varepsilon\left(\sum_{\mathrm{T}=1}^{p} S_{\mathrm{T}}^{-}\right) \\
& \left(\sum_{i=1}^{n} X_{i j} \lambda_{j}+S_{i}^{-}-\alpha X_{i k}\right)=0, \quad S_{i}^{-} \geq 0 \\
& \left(\sum_{i=1}^{n} Y_{r} \lambda_{i}+S_{i}^{+}-Y_{\mathrm{r} i k}\right)=0, \quad S_{i}^{+} \geq 0 \\
& \left(\sum_{i=1}^{n} \lambda_{j}\right)=1, \quad \lambda_{i} \geq 0 \\
& j=1, \ldots, n ; \dot{r}=1, \ldots, p ; i=1, \ldots, m
\end{aligned}
$$

Burada;

$\alpha$ : Göreli etkinliği ölçülen " $\mathrm{k}$ " karar biriminin girdilerinin ne kadar azaltılabileceğini gösteren büzülme katsayısı,

$Y_{r k i}:$ k. karar birimi tarafından üretilen r. çıktı,

$X_{i, j}:$ k. karar birimi tarafından kullanılan i. girdi,

Yrj: j. karar birimi tarafından üretilen r. çıktı,

$X_{1, j}:$ j. karar birimi tarafindan kullanılan i. girdi,

$\lambda_{j}$ : j. karar biriminin aldığ yoğunluk değeri,

$S_{:}^{-}:$k. karar biriminin i. değerine ait atıl değer,

$S_{i}^{+}: k$. karar birimin r. değerine ait atıl değer,

$\varepsilon$ : Yeterince küçük pozitif bir sayı olarak tanımlanmaktadır(Özçelik \& Kandemir,2017:43-53).

\section{Süper Etkinlik Modeli}

VZA yöntemlerinde CCR ve BCC yöntemleri sadece etkin birimleri belirleyebilmekte, ancak etkin birimlerin sıralanmasına yani etkinlik derecelerinin bulunmasına izin vermemektedir. Bu amaçla geliştirilen yöntemlerden Süper Etkinlik 
Modeli kurucularının baş harflerini alarak AP Modeli (Andersen ve Petersen) olarak literatürde yerini almaktadır. (Koçak\& Çilingirtürk, 2011, ss.166-175)

AP modeli yapı olarak CCR ve BCC modellerine benzer olmakla birlikte bu modelin CCR ve BCC modellerinden tek fark1 değerlendirme altındaki birimin süper etkinlik modelinde referans kümede yer almamasıdır.

Süper Etkinlik modeli aşağıdaki gibi tanımlanır:

$$
\begin{aligned}
& \sum_{i=1}^{i} \lambda_{j} x_{i j} \leq 8_{0} x_{i 0}, \quad i=1,2, \ldots, m \\
& \text { i } \\
& \sum_{i=1}^{i} \lambda_{j} y_{r i} \geq y_{r 3}, \quad r=1,2, \ldots, s \\
& \text { iFill } \\
& \sum_{i=1}^{i} \lambda_{j}=1, \quad \lambda_{j} \geq 0, \quad j=1,2, \ldots, n \text { (Doğan,2015, s.193) }
\end{aligned}
$$

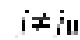

\section{Uygulama ve Bulgular}

\subsection{Yöntem ve Veri}

Bu çalışmada; Türk Sigorta Sektöründe 2014-2016 döneminde hayat dış1 branşlarda faaliyet gösteren sigorta şirketlerinin etkinliği benzer girdiler kullanarak çıktı ya da çıtılar ortaya koymakla sorumlu karar noktalarının göreceli etkinliklerini değerlendirmek için kullanılan bir yöntem olan Veri Zarflama Analizi (VZA) ile değerlendirilmiştir.

VZA' da temel 3 yöntemden biri olan ölçeğe göre değişken getiri varsayımına dayanan BCC modeli girdi eksenli olarak kullanılmış olup kurulan model DEASOLVER programı ile çözülmüştür.

Çalışmada veri olarak literatürde performans değerlemede kabul görmüş finansal ve üretim değişkenlerine ait veriler T.C. Hazine müsteşarlı̆̆ tarafından yayınlanan y1llık raporlardan elde edilmiştir (https://www.hazine.gov.tr/tr ).

Tablo 1. Değişkenler Tablosu

\begin{tabular}{|c|c|c|}
\hline \multirow{2}{*}{ Finansal Değişkenler } & ÖZKK & Özkaynak Karlılı̆̆ı \\
\cline { 2 - 3 } & DKZ & Dönem Kar/Zararı \\
\hline \multirow{3}{*}{ Üretim Değişkenleri } & PBG & Toplam Gider/Prim \\
\cline { 2 - 3 } & AS & Acente, Broker ve Banka Acente Sayısı \\
\cline { 2 - 3 } & TPÜ & Toplam Prim Üretimi \\
\cline { 2 - 3 } & TTÖ & Toplam Tazminat Ödemeleri \\
\hline
\end{tabular}

Çalışmada sektörde hayat dışı branşlarda hizmet veren sigorta şirketlerinden bazıları özel alanlarda sigorta hizmeti vermesi, faaliyetlerinin durdurulması, ara dönem birleşmeleri gibi sebeplerle analiz dışında bırakılarak 2014 yılı için 29, 2015 yılı için 27, 2016 yılı için ise 26 şirket çalışmanın örnek uzayını oluşturmuştur.

\subsection{Uygulama}

\section{Karar Verme Birimlerinin Seçimi}

Aynı tür girdileri kullanarak aynı tür çıktıları üreten karar verme birimlerinin birbirlerine göre göreli etkinliklerini ölçmek için tasarlanmış bir yöntem olan Veri Zarflama Analizi ile birbirine benzeyen girdiler yardımı ile birbirine benzeyen çıktılar üreten işletme, kurum, firma, şirket gibi göreli etkinliği incelenen organizasyonel birimlere karar verme birimi denir (Sar1, 2015, s.2). 
Bu çalışmada karar verme birimleri Türk Sigorta Sektöründe elementer branşlarda faaliyet gösteren sigorta şirketleri olarak belirlenmiştir. Çalışmada kullanılacak karar verme birimi sayısının yeterli olmasının etkinlik ölçümünün anlamlı sonuçlar vermesi açısından önemli olduğu daha önce ifade edilmişti.

Karar verme birimi sayısı yıllar itibarıyla,

- Girdi ve çıktı sayısının toplamının en az üç katı olması gerektiği

- En az (girdi sayısı +çıktı sayısı+1) kadar olması gerektiği

yönündeki iki ilkeyi de sağlamaktadır (Sarı, 2015, s.18).

\section{Modelde Kullanılacak Girdilerin ve Çıktıların Seçilmesi}

VZA her ne kadar çoklu girdi ve çıktının kullanılmasına olanak tanısa da, değişkenlerin seçimine ve veri hatalarına karşı son derece duyarlı bir analiz olup modele çok fazla girdi ve çıktı eklenmesi, VZA'nın verimli ve verimsiz birimleri birbirinden ayrıştırma yeteneğini düşürmektedir(Aydemir,2002, ss.58,89).Dolayısıyla çalışmada literatürde performans değerlemede kabul görmüş optimum finansal ve üretim değişkenleri girdi ve çıktı değişkenleri olarak belirlenmiş olup söz konusu girdi/çıktılara ait veriler T.C. Hazine müsteşarlı̆̆ edilmiştir.

Tablo 2. Girdi/ Çıktı Tablosu

\begin{tabular}{|l|l|}
\hline Girdiler & $\begin{array}{l}\text { Özkaynak Karlıı̆̆ı* (ÖZKK) } \\
\text { Toplam Gider/Prim (PBG) } \\
\text { Acente, Broker ve Banka Acente Sayısı(AS) }\end{array}$ \\
\hline Çıktılar & $\begin{array}{l}\text { Dönem Kar/Zararı (DKZ) } \\
\text { Toplam Prim Üretimi (TPÜ) } \\
\text { Toplam Tazminat Ödemeleri (TTÖ) }\end{array}$ \\
\hline
\end{tabular}

*Özkaynak Karlılığı: Bu oran işletme sahibinin işletmeye yatırmış olduğu paranın ne kadarının verimli kullanıldığını gösterir.

\section{Veri Zarflama Analizi Modelinin Belirlenmesi ve Etkinliğin Ölçülmesi}

CCR modeli ölçeğe göre sabit getiri(Constant Return to Scale) varsayımı altında toplam etkinliği ölçerken, BCC modeli ölçeğe göre değişken getiri (Variable Return to Scale) varsayımı altında benzer ölçekteki birimleri birbirleriyle kıyaslayarak teknik etkinliği ölçmektedir (Cingi veTarım,2000,s.8).Bu çalışmada sektörün mukayeseli değerlemesi merkeze konduğu için BCC modeli analizde tercih edilmiştir.

\section{Etkinlik Değerlerinin Belirlenmesi}

Şirket bazında etkinlik değerlerindeki değişimi izlemek için yıllara göre yapılan analiz sonuçları tek bir tabloda toplanarak Tablo 3'de özetlenmiştir. Söz konusu tablodan da görüldüğü gibi 2014 yılında 12, 2015 yılında 13 ve 2016 yılında ise 5 şirket etkindir. 2014 y1lında Zürich, Anadolu, Türk Nippon, Güneş, Generali, Ak Sigorta, Ziraat, Axa, Allianz, Dubai Starr, Mapfre Genel ve Koru sigorta şirketleri etkin iken; 2015 yılında Demir, Aig, Eureko, Anadolu, Mapfre Genel, Türk Nippon, Dubai Starr, Groupama, Ziraat, Axa, Sbn, Allianz ve Koru sigorta şirketleri etkindir. 2016 yılında ise Ziraat, Anadolu, Türk Nippon, Allianz ve Koru olmak üzere sadece 5 şirketin etkin olduğu görülmektedir.

Çalışma dönemi boyunca her 3 yılda da etkin olmayı sürdüren şirketlerin ise Ziraat, Anadolu, Türk Nippon, Allianz ve Koru olduğu görülmektedir. Söz konusu etkin 
şirket sayısındaki düşüşte 2016 yılında trafik sigortaları ile ilgili düzenlemelerin etkili olduğu düşünülmektedir.

Özetle 2014 yılında hayat dışı branşlarda hizmet veren sigorta şirketlerinin $\% 41$ 'i, 2015 yılında \%48'i ve 2016 y1lında ise \%19'unun etkin olduğu görülmüştür.

Tablo 3. Girdi Yönlü BBC Süper Etkinlik (Super-Radial(Super-BCC-I)) modeli çıtıları

\begin{tabular}{|r|l|c|l|l|l|c|}
\hline & \multicolumn{2}{|c|}{$\mathbf{2 0 1 4}$} & \multicolumn{2}{c|}{$\mathbf{2 0 1 5}$} & \multicolumn{2}{c|}{$\mathbf{2 0 1 6}$} \\
\hline & Şirket Adı & $\begin{array}{c}\text { Etkinlik } \\
\text { Skoru }\end{array}$ & Şirket Adı & $\begin{array}{c}\text { Etkinlik } \\
\text { Skoru }\end{array}$ & Şirket Adı & $\begin{array}{c}\text { Etkinlik } \\
\text { Skoru }\end{array}$ \\
\hline $\mathbf{1}$ & Zürich & 2,350 & Demir & 2,364 & Ziraat & 2,524 \\
\hline $\mathbf{2}$ & Anadolu & 1,283 & Aig & 2,007 & Anadolu & 1,221 \\
\hline $\mathbf{3}$ & Türk Nippon & 1,129 & Eureko & 1,815 & Türk Nippon & 1,144 \\
\hline $\mathbf{4}$ & Güneş & 1,086 & Anadolu & 1,469 & Allianz & 1,000 \\
\hline $\mathbf{5}$ & Generali & 1,036 & Mapfre Genel & 1,449 & Koru & 1,000 \\
\hline $\mathbf{6}$ & Aksıgorta & 1,035 & Türk Nippon & 1,194 & Dubai Starr & 0,951 \\
\hline $\mathbf{7}$ & Ziraat & 1,000 & Dubai Starr & 1,108 & Eureko & 0,930 \\
\hline $\mathbf{8}$ & Axa & 1,000 & Groupama & 1,066 & AIG & 0,884 \\
\hline $\mathbf{9}$ & Allianz & 1,000 & Ziraat & 1,000 & Axa & 0,849 \\
\hline $\mathbf{1 0}$ & Dubai Starr & 1,000 & Axa & 1,000 & Ray & 0,803 \\
\hline $\mathbf{1 1}$ & Mapfre Genel & 1,000 & Sbn & 1,000 & Liberty & 0,788 \\
\hline $\mathbf{1 2}$ & Koru & 1,000 & Allianz. & 1,000 & Güneş & 0,784 \\
\hline $\mathbf{1 3}$ & Ray & 0,992 & Koru & 1,000 & Ankara & 0,784 \\
\hline $\mathbf{1 4}$ & Aig & 0,966 & Sompo Japan & 0,985 & Aksigorta & 0,783 \\
\hline $\mathbf{1 5}$ & Demir & 0,946 & Ray & 0,896 & Halk & 0,775 \\
\hline $\mathbf{1 6}$ & Eureko & 0,882 & Işı & 0,884 & Sompo Japan & 0,759 \\
\hline $\mathbf{1 7}$ & Ege / Euro & 0,837 & Liberty & 0,881 & Mapfre Genel & 0,734 \\
\hline $\mathbf{1 8}$ & Hdi & 0,801 & Zürich & 0,801 & Sbn & 0,703 \\
\hline $\mathbf{1 9}$ & Neova & 0,797 & Halk & 0,784 & Generali & 0,629 \\
\hline $\mathbf{2 0}$ & Groupama & 0,773 & Ankara & 0,775 & Hdi & 0,623 \\
\hline $\mathbf{2 1}$ & Sbn & 0,772 & Güneş & 0,752 & Zürich & 0,600 \\
\hline $\mathbf{2 2}$ & Halk & 0,745 & Ergo & 0,744 & Groupama & 0,594 \\
\hline $\mathbf{2 3}$ & Ankara & 0,700 & Hdi & 0,710 & Ergo & 0,585 \\
\hline $\mathbf{2 4}$ & Sompo Japan & 0,694 & Aksigorta & 0,685 & Neova & 0,576 \\
\hline $\mathbf{2 5}$ & Ergo & 0,689 & Neova & 0,644 & Iş1k & 0,501 \\
\hline $\mathbf{2 6}$ & Iş1k & 0,643 & Aviva (Unico) & 0,503 & Aviva (Unico) & 0,500 \\
\hline $\mathbf{2 7}$ & Liberty & 0,472 & Generali & 0,465 & & \\
\hline $\mathbf{2 8}$ & Aviva & 0,320 & & & & \\
\hline $\mathbf{2 9}$ & Hur & 0,319 & & & & \\
\hline
\end{tabular}

\section{Referans Kümelerinin Belirlenmesi,}

VZA yönteminde daha önce de ifade edildiği gibi etkin olamayan karar birimlerinin etkin olanların uyguladıkları yöntemler ile aynı etkinlik düzeyine ulaşabileceği varsayımı söz konusudur ve ayrıca referans kümeleri, etkin olmayan karar birimlerinin etkinliklerini arttırmak için yol gösterici olması sebebiyle de önemlidir. $\mathrm{Bu}$ bağlamda Tablo 4'te sadece 2016 y1lı için etkin olmayan sigorta şirketlerinin etkinliklerini arttırmaları için referans kümelerindeki sigorta şirketleri yer almaktadır. Bununla birlikte referans kümelerindeki şirketlerin sadece analizde kullanılan girdi ve çıktılar ekseninde değil şirketlerin diğer uygulamaları ekseninde de değerlendirilmesi gerektiği unutulmamalıdır (Bakırcı, 2006, s.83). Analiz sonucunda 19 kez ZİRAAT Sigorta'nın, $13 \mathrm{kez}$ ANADOLU Sigorta'nın ve $10 \mathrm{kez}$ de ALLİANZ Sigorta' nın referans şirketler olarak belirlendiği görülmüsstür. Referans kümelerinde yer alan 
şirketlerin etkin şirketler olduğu istisna olarak AXA ve DUBAİ STAR sigorta şirketlerinin birer kez referans kümesinde yer aldığ görülmektedir.

Tablo 4. 2016 yılı için Referans Kümeleri

\begin{tabular}{|c|c|c|c|c|}
\hline Şirket Adı & \multicolumn{4}{|c|}{ Referans Kümeleri } \\
\hline AIG & ANADOLU & KORU & TÜRK NİPPON & ZİRAAT \\
\hline AK SİGORTA & ALLİANZ & KORU & ZİRAAT & \\
\hline \multicolumn{5}{|l|}{ ALLİANZ } \\
\hline ANADOLU & ALLIANZ & AXA & KORU & \\
\hline ANKARA & ANADOLU & KORU & TÜRK NIPPON & ZİRAAT \\
\hline AVIVA (UNICO) & ANADOLU & KORU & TÜRK NİPPON & ZIRAAT \\
\hline AXA & ALLİANZ & ANADOLU & KORU & ZIRAAT \\
\hline DUBAİ STARR & KORU & TÜRK NIPPPON & ZIRAAT & \\
\hline ERGO & ANADOLU & KORU & TÜRK NIPPPON & \\
\hline EUREKO & ANADOLU & KORU & TÜRK NIPPON & ZİRAAT \\
\hline GENERALI & ANADOLU & KORU & TÜRK NIPPON & \\
\hline GROUPAMA & ALLİANZ & KORU & ZIRAAT & \\
\hline GUNES & ALLİANZ & ANADOLU & KORU & ZİRAAT \\
\hline HALK & ANADOLU & KORU & TÜRK NIPPON & ZİRAAT \\
\hline HDİ & ALLİANZ & KORU & ZIRAAT & \\
\hline IŞIK & KORU & TÜRK NIPPON & ZIRAAT & \\
\hline \multicolumn{5}{|l|}{ KORU } \\
\hline LİBERTY & ANADOLU & KORU & TÜRK NIPPPON & \\
\hline MAPFRE GENEL & ANADOLU & KORU & TÜRK NIPPON & ZIRAAT \\
\hline NEOVA & ALLİANZ & KORU & ZIRAAT & \\
\hline RAY & ALLİANZ & KORU & ZİRAAT & \\
\hline SBN & KORU & TÜRK NIPPON & ZİRAAT & \\
\hline SOMPO JAPAN & ALLİANZ & ANADOLU & KORU & ZIRAAT \\
\hline TÜRK NIPPPON & DUBAİ STARR & KORU & ZIRAAT & \\
\hline ZIRAAT & ALLIANZ & TÜRK NIPPON & & \\
\hline ZURİCH & ANADOLU & KORU & TÜRK NIPPON & ZIRAAT \\
\hline
\end{tabular}

\section{Etkin Olmayan Karar Verme Birimleri İçin Stratejilerin Belirlenmesi,}

VZA' nin bir diğer önemli bulgusu da etkin olmayan karar birimlerine performanslarını iyileştirebilmeleri için ulaşılabilir hedefler koymasıdır. Etkin olmayan karar birimlerinin göreli olarak etkin birimlerin uyguladığı yöntemleri uygulayarak aynı etkinlik düzeyine ulaşabilecekleri varsayılır. Tablo 5'de 2016 yılı için etkin olmayan karar verme birimlerine dair potansiyel iyileştirme değerleri verilmektedir. Bu tabloda yer alan Güneş sigortaya ait değerlendirme örnek olarak yapılacaktır. Güneş sigorta'nın https://www.hazine.gov.tr/tr' den elde edilen 2016 yılına ait verileri aşağıdaki gibi olup potansiyel iyileştirme tablosu ile değerlendirildiğinde şirketin öz kaynak karlılığında etkinliği yakaladığı ancak prim başına gider kaleminde \%21'lik düşüş hedeflemesi gerektiği görülmektedir. Ayrıca 2869 olan aracı sayısını da 2250 ye düşürmesi gerektiği ya da 2250 aracı ile gerçekleştirilecek işi 2869 aracı ile yaptığı yani aracıların performanslarında problem olduğu tespit edilmektedir.

Tazminat ödemelerinde etkinliği yakalayan şirketin Dönem $\mathrm{K} / \mathrm{Z}$ ve prim üretiminde ciddi iyileştirmelere gitmesi gerekmektedir. 


\begin{tabular}{|l|c|c|c|c|c|c|}
\hline & $\begin{array}{c}\text { Özkaynak } \\
\text { Karlılığı }\end{array}$ & $\begin{array}{c}\text { Topl. } \\
\text { Gider/Prim }\end{array}$ & Aracı Sayısı & Dönem K/Z & Topl. Prim & Tazminat \\
\hline GÜNEŞ & $-0,117$ & 0,600 & 2869 & -50762 & 1372978 & 899082 \\
\hline
\end{tabular}

Sektörün potansiyel iyileştirme tablosu genel olarak değerlendirildiğinde 2016 yılı için 5 şirket hariç diğerlerinin tazminat ödemelerinde etkinliği yakaladığı görülmektedir. Toplam prim üretiminde ise 5 şirket hariç diğerlerinin üretimlerinin yetersiz olduğu ve prim üretimlerini arttırmaları gerektiği dönem $\mathrm{K} / \mathrm{Z}$ da ise sektörün etkinliği yakaladığı ancak artış hedefli stratejiler üretmesi gerektiği sonucuna ulaşıllmıştır.

Tablo 5. 2016 yılı için Etkin Olmayan Karar Verme Birimlerine Dair Potansiyel İyileştirme Tablosu

\begin{tabular}{|c|c|c|c|c|c|c|c|c|c|c|c|c|}
\hline & \multicolumn{2}{|c|}{$\begin{array}{c}\text { Öz kaynak } \\
\text { Karlılığı }\end{array}$} & \multicolumn{2}{|c|}{$\begin{array}{c}\text { Toplam } \\
\text { Gider/Prim }\end{array}$} & \multicolumn{2}{|c|}{$\begin{array}{l}\text { Aracı } \\
\text { Sayısı } \\
\end{array}$} & \multicolumn{2}{|c|}{ Dönem K/Z } & \multicolumn{2}{|c|}{$\begin{array}{c}\text { Toplam } \\
\text { Prim } \\
\end{array}$} & \multicolumn{2}{|c|}{ Tazminat } \\
\hline & $\mathbf{H}^{*}$ & $\begin{array}{l}D^{* *} \\
(\%)\end{array}$ & H & $\begin{array}{c}\text { D } \\
(\%)\end{array}$ & H & $\begin{array}{c}\text { D } \\
(\%)\end{array}$ & H & $\begin{array}{c}\text { D } \\
(\%)\end{array}$ & H & $\begin{array}{c}\text { D } \\
(\%)\end{array}$ & H & $\begin{array}{c}\text { D } \\
(\%)\end{array}$ \\
\hline Aig & 0,14 & $-11,6$ & 0,39 & $-11,6$ & 647,7 & $-11,6$ & 32833,4 & 38,9 & 421952,9 & 37,2 & 107766,2 & $\mathbf{0 , 0}$ \\
\hline Ak & 0,09 & $-21,7$ & 0,45 & $-21,7$ & 2493,5 & $-24,3$ & 196545,4 & 308,1 & 2630609,0 & 38,8 & 1014511,0 & $\mathbf{0 , 0}$ \\
\hline Allianz & 0,23 & 0,0 & 0,71 & 0,0 & 6066,0 & 0,0 & 376155,6 & 0,0 & 5775138,0 & 0,0 & 2805431,0 & $\mathbf{0 , 0}$ \\
\hline Anadolu & 0,09 & 22,1 & 0,77 & 1,7 & 5621,9 & 22,1 & 301995,7 & 243,7 & 5095129,0 & 13,6 & 2598964,0 & $\mathbf{0 , 0}$ \\
\hline Ankara & $-0,22$ & $-161,5$ & 0,46 & $-21,6$ & 779,5 & $-21,6$ & 38347,0 & 0,0 & 579020,8 & 83,8 & 190663,6 & $\mathbf{0 , 0}$ \\
\hline Aviva (Unıco) & $-0,24$ & 0,0 & 0,45 & $-50,0$ & 868,3 & $-50,0$ & 53852,1 & 283,3 & 770223,2 & 157,9 & 238142,7 & $\mathbf{0 , 0}$ \\
\hline Axa & 0,09 & $-15,1$ & 0,69 & $-26,0$ & 4122,1 & $-15,1$ & 102618,8 & 0,0 & 4065107,0 & 14,1 & 2262866,0 & $\mathbf{0 , 0}$ \\
\hline Dubai & 0,09 & $-4,9$ & 0,40 & $-4,9$ & 621,9 & $-4,9$ & 27817,5 & 516,5 & 362238,8 & 98,6 & 94562,9 & 2,0 \\
\hline Ergo & $-0,80$ & 0,0 & 0,63 & $-41,5$ & 1450,0 & $-41,5$ & 29286,7 & 120,5 & 1132302,0 & 37,8 & 627281,5 & $\mathbf{0 , 0}$ \\
\hline Eureko & $-0,18$ & $-228,7$ & 0,49 & $-7,0$ & 1591,8 & $-7,0$ & 74071,3 & $\mathbf{0 , 0}$ & 1585126,0 & 28,4 & 687190,4 & $\mathbf{0 , 0}$ \\
\hline Generali & $-0,69$ & 0,0 & 0,54 & $-37,1$ & 637,8 & $-37,1$ & 15459,3 & 220,7 & 281663,3 & 43,5 & 116752,9 & $\mathbf{0 , 0}$ \\
\hline Groupama & 0,01 & $-40,6$ & 0,42 & $-40,6$ & 1871,6 & $-60,6$ & 163552,7 & 999,9 & 2068236,0 & 79,8 & 703567,8 & $\mathbf{0 , 0}$ \\
\hline Güneş & $-0,09$ & 0,0 & 0,47 & $-21,6$ & 2249,8 & $-21,6$ & 177741,5 & 450,1 & 2374881,0 & 73,0 & 899081,7 & $\mathbf{0 , 0}$ \\
\hline Halk & $-0,78$ & $-829,9$ & 0,58 & $-22,5$ & 1224,3 & $-22,5$ & 45350,7 & 106,1 & 1035484,0 & 0,0 & 473509,8 & $\mathbf{0 , 0}$ \\
\hline Hdı & 0,08 & $-37,7$ & 0,36 & $-37,7$ & 1265,6 & $-49,6$ & 135610,5 & 231,6 & 1556690,0 & 78,8 & 398523,9 & $\mathbf{0 , 0}$ \\
\hline Işık & 0,09 & $-49,9$ & 0,40 & $-49,9$ & 622,8 & $-49,9$ & 28151,1 & 94,1 & 365424,2 & 139,2 & 94991,6 & 4,0 \\
\hline Koru & $-3,53$ & 0,0 & 1,00 & 0,0 & 570,0 & 0,0 & 3660,3 & 0,0 & 104486,0 & 0,0 & 97393,3 & $\mathbf{0 , 0}$ \\
\hline Liberty & $-1,55$ & 0,0 & 0,68 & $-21,2$ & 632,3 & $-21,2$ & 12146,4 & 215,2 & 243841,0 & 30,5 & 120364,4 & $\mathbf{0 , 0}$ \\
\hline Mapfre & 0,11 & $-26,6$ & 0,53 & $-26,6$ & 2689,3 & $-26,6$ & 103382,5 & 3,7 & 2813766,0 & 0,7 & 1368023,0 & $\mathbf{0 , 0}$ \\
\hline Neova & 0,26 & $-42,4$ & 0,31 & $-42,4$ & 1142,7 & $-53,7$ & 134654,3 & 51,0 & 1493778,0 & 48,5 & 334388,2 & $\mathbf{0 , 0}$ \\
\hline Ray & 0,21 & $-19,7$ & 0,31 & $-19,7$ & 1014,7 & $-30,7$ & 126841,2 & 285,7 & 1369171,0 & 140,8 & 270887,9 & $\mathbf{0 , 0}$ \\
\hline Sbn & 0,30 & $-29,7$ & 0,34 & $-29,7$ & 693,8 & $-29,7$ & 53745,6 & 145,7 & 613176,0 & 278,5 & 123689,8 & 106,9 \\
\hline Sompo J. & 0,26 & $-24,1$ & 0,40 & $-25,2$ & 1993,2 & $-24,1$ & 142021,9 & $\mathbf{0 , 0}$ & 2236156,0 & 0,0 & 846217,6 & 23,9 \\
\hline Türk Nipp. & 0,06 & $-85,2$ & 0,42 & 14,4 & 680,5 & 14,4 & 18683,8 & $\mathbf{0 , 0}$ & 312309,1 & 13,0 & 106375,0 & 31,0 \\
\hline Ziraat & 0,33 & $-32,3$ & 0,47 & 88,8 & 2282,0 & 152,4 & 128912,4 & 0,0 & 1971896,0 & 47,4 & 921257,4 & 335,3 \\
\hline Zürich & $-0,06$ & $-198,6$ & 0,45 & $-40,0$ & 783,9 & $-40,0$ & 23535,7 & 105,7 & 481003,8 & 0,0 & 201411,1 & 0,0 \\
\hline
\end{tabular}

*H: Hedef, **D: Değişim 


\section{Sonuç ve Tartışma}

Küreselleşen dünyada ülke ekonomilerinde belirleyici olan finansal piyasalarda yaşanan rekabet etkinliğin önem kazanmasına sebep olmaktadır. Sigorta sektöründe yer alan şirketlerin performanslarını göreli olarak değerlendirmesi ve referans almaları gereken şirketleri/rakipleri belirlemesi ileriye dönük stratejiler üretmede ve risklerini yönetmede son derece önem arz etmektedir. Finansal piyasalarda performans değerlemesinde sıklıkla finansal oranlar kullanılmakta olup performans sonuçları etkinlik ve verimlilik ekseninde değerlendirilmektedir. Çalışmada Türk Sigorta Sektöründe son üç y1llık periyotta elementer branşlarda yer alan sigorta şirketlerine ait etkinlik düzeylerinin Veri Zarflama Analizi (VZA) ile belirlenmesi hedeflenmiştir. Bu değerlendirmenin rekabet gücü yüksek bir ekonomi yaratmada katkı sağlayacak yaklaşımlar üretmesi beklenmekte olup sektörün mukayeseli değerlemesi merkeze konduğu için BCC modeli analizde tercih edilmiştir.

Analiz sonuçları değerlendirildiğinde 2014 yılında 12, 2015 yılında 13 ve 2016 yılında ise 5 şirketin etkin olduğu görülmektedir. Çalışma dönemi boyunca her 3 yılda da etkin olmayı sürdüren şirketlerin ise Ziraat, Anadolu, Türk Nippon, Allianz ve Koru olduğu görülmektedir. Söz konusu etkin şirket sayısındaki düşüşte 2016 yılında trafik sigortaları ile ilgili düzenlemelerin etkili olduğu düşünülmektedir. Özetle 2014 yılında hayat dişı branşlarda hizmet veren sigorta şirketlerinin \%41'i, 2015 yılında \%48'i ve 2016 yılında ise \%19'unun etkin olduğu görülmüştür.

Analiz sonucunda 2016 yılı için 19 kez ZIRAAT Sigorta'nın, 13 kez ANADOLU Sigorta'nın ve $10 \mathrm{kez}$ de ALLIANZ Sigorta'nın referans şirketler olarak belirlendiği görülmüştür. Referans kümelerinde yer alan şirketlerin etkin şirketler olduğu istisna olarak AXA ve DUBAI STAR sigorta şirketlerinin birer kez referans kümesinde yer aldığı görülmektedir.

Sektörün potansiyel iyileştirme oranları genel olarak değerlendirildiğinde 2016 yılı için tazminat ödemelerinde etkinliği yakaladığı görülmektedir. Toplam prim üretimlerinin yetersiz olduğu ve prim üretimlerini arttırmaları gerektiği dönem $\mathrm{K} / \mathrm{Z}$ da ise sektörün etkinliği yakaladığı ancak artış hedefli stratejiler üretmesi gerektiği sonucuna ulaşılmıştır.

Analiz sonuçlarına göre tazminat ödemelerinde sektörün etkinliği yakalamış olması müşterilerin memnuniyet ve beklentilerini karşılamakta olup portföy sürdürülebilirliği ekseninde şirketlerin performanslarına olumlu katkı sağlamaktadır. Bununla birlikte toplam prim üretimindeki yetersizlik ve satış kanallarındaki düşük sonuçlar şirketlerin performanslarını olumsuz yönde etkilemekte olduğu görülmektedir. Dolayısıyla satış kanallarında kalitenin yükseltilmesinin prim üretiminde de artışa yol açarak özelde şirket genelde sektör performansını olumlu yönde etkileyeceği düşünülmektedir. Toplam prim üretiminin artmasının ayrıca dolaylı alarak da kar zarar kriterinde de iyileşme sağlayacağı için şirketlerin ve sektörün performansını arttıracağ1 öngörülmektedir. 


\section{Kaynakça}

Akel, V., Torun, T., \& Aksoy, B. (2017). Türkiye'de Hayat Dışı Sigortacılık Sektöründe Kârlılık, Sermaye Yapısı ve Yoğunlaşma İlişkisine Yönelik Ampirik Bir Uygulama. International Journal of Finance \& Banking Studies (2147-4486), $5(5), 1-15$.

Akyüz, Y., Yıldız, F., \& Kaya, Z. (2013). "Veri Zarflama Analizinde (VZA) Malmquist Endeksi ile Toplam Faktör Verimlilik Ölçümü: IMKB'ye Kayıtlı Mevduat Bankaları Üzerine Bir Uygulama”, Atatürk Üniversitesi İktisadi ve İdari Bilimler Dergisi, 27(4), 110-130.

Altan M. (2010). "Türk Sigortacılık Sektöründe Etkinlik :Veri Zarflama Analizi Yöntemi ile Bir Uygulama", Gazi University Journal Of Economics \& Administrative Sciences [serial online]185-204. Available from: Business Source Complete, Ipswich, MA. Accessed July 29, 2017

Atıcı, Y, Şimşek, A, Ulucan, P , Tosun, D . (2016). "Veri Zarflama Analizi İle Uygulama Alanı Türkiye Olan Performans Ölçümü Çalışmaları: Literatür Araştırması Ve Değerlendirmeler”, Verimlilik Dergisi, 0 (1), 7-47.

Aydemir, Z. C. (2002). "Bölgesel Rekabet Edebilirlik Kapsamında İllerin Kaynak Kullanım Görece Verimlilikleri: Veri Zarflama Analizi Uygulaması”, Uzmanlık Tezi, DPT:2664

Bakırcı, F. (2006). Üretimde Etkinlik ve Verimlilik Ölçümü Veri Zarflama Analizi Teori ve Uygulama. Atlas Yayınları, Ankara.

Banker, R. D., Charnes, A., \& Cooper, W. W. (1984). "Some Models For Estimating Technical and Scale Inefficiencies In Data Envelopment Analysis", Management Science, 30(9), 1078-1092.

Barros, C. P., Nektarios, M., \& Assaf, A. (2010). "Efficiency in the Greek Insurance Industry. European Journal of Operational Research”, 205(2), 431-436.

Behdioğlu, S., \& ÖZCAN, A. G. G. (2009). "Veri Zarflama Analizi ve Bankacılık Sektöründe Bir Uygulama", Süleyman Demirel Üniversitesi İktisadi ve İdari Bilimler Fakültesi Dergisi, 14(3), 301-326.

Bülbül, S.,Akhisar, İ.(2005).“Türk Sigorta Şirketlerinin Etkinliğinin Veri Zarflama Analizi İle Araştırılması”, VII.Ulusal Ekonometri ve İstatistik Sempozyumu,2627.

Charnes, A., Cooper, W. W., \& Rhodes, E. (1978). "Measuring The Efficiency of Decision Making Units", European Journal of Operational Research, 2(6), 429444.

Chen, Y., Cook, W. D., Li, N., \& Zhu, J. (2009). “Additive Efficiency Decomposition In Two-Stage DEA", European Journal of Operational Research, 196(3), 11701176.

Cingi, S., \& Tarım, A. (2000). "Türk Banka Sisteminde Performans Ölçümü DeaMalmquist Tfp Endeksi Uygulaması”, Türkiye Bankalar Birliği Araştırma Tebliğleri Serisi, 1, 1-34. 
Cummins, J. D., Weiss, M. A., Xie, X., \& Zi, H. (2010). "Economies of Scope in Financial Services: A DEA Efficiency Analysis of the US Insurance Industry", Journal of Banking \& Finance, 34(7), 1525-1539.

Çakın,E.(2017). “Ükelerin İnovasyon Performansının Ölçülmesinde Yapay Sinir Ağları, Bulanık Dematel Tabanlı Analitik Ağ Süreci ve Ağırlık Kısıtlı Veri Zarflama Analizi Yaklaşımlarının Bütünleşik Olarak Kullanılması ve Bir Uygulama", Yayınlanmış Doktora tezi, Dokuz Eylül Üniversitesi ,Sosyal Bilimler Enstitüsü, İzmir, Turkey.

Çetintaş, H., \& Biç, Ö. F. (2012). “Türkiye'de Sigortacılık Sektörünün Etkinlik Analizi”, TISK Academy/TISK Akademi, 7(14), 125-154.

Çiftçi, D. H. (2013). "Türk Sigorta Sektörünün Sorunları; DEA Analizi ile Türk Sigorta Şirketlerinin Etkinlik Düzeylerinin Belirlenmesi”, Çukurova Üniversitesi. Çukurova Üniversitesi Sosyal Bilimler Enstitüsü Dergisi. Volume: 13, Issue: 1, 121-149.

Dalkılıç, N. (2012). “Türkiye'de Hayat Dışı Sigortacılık sektöründe Etkinlik Analizi”, Journal Of Accounting \& Finance, (55), 71-89.

Doğan, N. Ö. (2015). "VZA Süper Etkinlik Modelleri İle Etkinlik Ölçümü: Kapadokya'da Faaliyet Gösteren Balon İşletmeleri Üzerine Bir Uygulama", Atatürk Üniversitesi İktisadi ve İdari Bilimler Dergisi, 29(1),187-203

Eroğlu, Y., \& Seçkiner, S. U. (2017). "Rüzgâr Çiftliklerinde Veri Zarflama Analizi ve Malmquist Endeksi Yaklaşımları İle Performans Analizi”, Pamukkale University Journal of Engineering Sciences, 23(1), 45-54.

Farrell, M. J. (1957). "The Measurement of Productive Efficiency", Journal of the Royal Statistical Society, Series A (General), 120(3), 253-290.

Girginer, N., Yalam, A., \& Kaygisiz, Z. (2007). "Veri Zarflama Analizi ve Kümeleme Analizi İle Türkiye Sigortacılık Sektöründeki Firmaların Performanslarının Karşılaştırılması", İktisat İşletme ve Finans, 22(261), 100-113.

Kilickaplan, S., \& Karpat, G. (2013). “Türkiye Hayat Sigortası Sektöründe Etkinliğin İncelenmesi”, Dokuz Eylül Üniversitesi İktisadi ve İdari Bilimler Fakültesi Dergisi, 19(1),1-14.

Koçak, H., \& Çilingirtürk, A. M. (2011). “AB Ülkeleri ve Aday Ülkelerin Kaynak Kullanımında Etkinliklerinin Karşılaştırmalı Analizi”, Istanbul University Journal of the School of Business Administration, 40(2), 167-185.

Köse, A. (2010). “Türk Sigorta Sektörü Hayat ve Emeklilik Şirketlerinin Etkinlik Analizi”, Journal of Academic Studies, 12(44),85-100.

Liu, J. S., Lu, L. Y., Lu, W. M., \& Lin, B. J. (2013). “A Survey of DEA Applications”, Omega, 41(5), 893-902.

Liu, J. S., Lu, L. Y., Lu, W. M., \& Lin, B. J. (2013). "Data Envelopment Analysis 1978-2010: A Citation-Based Literature Survey", Omega, 41(1), 3-15.

Luhnen, M. (2009). "Determinants of Efficiency and Productivity In German PropertyLiability Insurance: Evidence for 1995-2006", The Geneva Papers on Risk and Insurance-Issues and Practice, 34(3), 483-505. 
Mahlberg, B., \& Url, T. (2003). "Effects of The Single Market On The Austrian Insurance Industry", Empirical Economics, 28(4), 813-838.

Özcan, A. İ. (2005). “Celal Bayar Üniversitesi’ne Bağlı Meslek Yüksekokullarının Etkinliklerinin Veri Zarflama Analizi ile Ölçülmesi”, Yayınlanmamış Yüksek Lisans Tezi, Celal Bayar Üniversitesi Sosyal Bilimler Enstitüsü, Manisa.

Özçelik,H., \& Kandemir,B. (2017). "Veri Zarflama Analizi ve İmalat Sektöründe Bir Uygulama", The Journal of Faculty of Economics and Administrative Sciences Y.2017, Vol.22, No.1, 43-53.

Özdağoğlu, A., Yakut, E., \& Bahar, S. (2017). "Türk Bankacılık Sektörünün Performans Değerlendirmesinde Entropik Ağırlıklarla Veri Zarflama Analizi”, Dokuz Eylül Üniversitesi İşletme Fakültesi Dergisi, 1-28

Özden, Ü. H. (2008). "Veri Zarflama Analizi (VZA) ile Türkiye'deki Vakıf Üniversitelerinin Etkinliğinin Ölçülmesi”, İstanbul Üniversitesi İşletme Fakültesi Dergisi, Cilt:37, Sayı:2, 167-185.

Ramanathan, R. (2003). “An Introduction to Data Envelopment Analysis: A Tool for Performance Measurement”, New Delhi: Sage Publications Pvt. Ltd.

Sarı,Z.(2015). "Veri zarflama analizi ve bir uygulama”, Yayınlanmış Yüksek Lisans tezi, Hacettepe Üniversitesi,,Fen Bilimleri Enstitüsü,Ankara,Turkey.

Shujie, Y. A. O., Zhongwei, H., \& Genfu, F. E. N. G. (2007). "On Technical Efficiency of China's Insurance Industry After WTO Accession”, China Economic Review, 18(1), 66-86.

Turgutlu, E., Kök, R., \& Kasman, A. (2007). "Türk Sigortacıllk Şirketlerinde Etkinlik: Deterministik ve Şans Kısıtlı Veri Zarflama Analizi”, İktisat İşletme ve Finans, 22(251), 85-102.

Yiğit, V., \& Esen, H. (2017). "Pabon Lasso Modeli ve Veri Zarflama Analizi ile Hastanelerde Performans Ölçümü Performance Measurement in Hospitals with Pabon Lasso Model and Data Envelopment Analysis", SDÜ Sağlık Bilimleri Enstitüsü Dergisi, 1-7

\section{Internet Kaynakları}

https://www.hazine.gov.tr/tr , (11.12.2017) 


\title{
Evaluation Of Turkish Insurance Sector In Non-Life Insurance With Data Envelopment Analysis
}

\author{
Seher A.Tezergil \\ Marmara University \\ School of Banking and Insurance \\ İstanbul, Turkey \\ orcid.org/ 0000-0002-0228-724X \\ stezergil@marmara.edu.tr
}

\section{Extensive Summary}

\section{Introduction}

By the fact of the globalization, competition in financial markets forces the stakeholders to use their resources more effectively. It is of great importance that the corporations have to evaluate their performances on competitively prized markets through the indicators, such as profitability, growth rates, efficiency and productivity. Therefore, the ability of self- determining the relative efficiency of companies within the rivalry has become extremely important in generating prospective strategies and managing their risks. In financial markets, financial ratios are the most used performance indicators where performance results are evaluated in terms of efficiency.

\section{Methodology}

In this study, it was aimed to determine the efficiency levels of the insurance companies in elementary branches in the last three years period with Data Envelopment Analysis (DEA). DEA, as a linear programming based method, is known as a nonparametric efficiency measurement method that evaluates the relative activities of decision units producing outputs with similar inputs. Financial and non-financial indicators within the related literature were used in the study. The established model which is based on a variable return-based assumption, Banker-Charnes-Cooper (BCC) model, was solved by the DEA-SOLVER program.

\section{Findings}

When the analysis results are evaluated, it is seen that 12 insurance companies, 13 insurance companies and 5 insurance companies are efficient, respectively in 2014, 2015,2016 . Additionally, it is found that the regulations on traffic insurances in 2016 will be efficient in the decrease in the number of effective companies. Besides, $41 \%$ of insurance companies that serve in non-life branches in 2014, 48\% in 2015 and $19 \%$ in 2016 were found to be efficient. As a result of the analysis, it is found that ZIRAAT Insurance has been defined as reference companies 19 times; ANADOLU Insurance as 13 times as reference companies and ALLIANZ Insurance 10 times as reference companies, particularly in the year of 2016. It is seen that AXA and DUBAI STAR insurance companies are included only once in the reference group, with the exception that the companies in the reference clusters are efficient companies.

\section{Discussion}

When the potential improvement rates of the sector are evaluated in general, it is seen that sector has been efficient in compensation payments, in the year of 2016. The 
findings illustrate that; total premium production is inadequate, premium production should be increased, the periodic profit / loss ratio has reached to the level that the sector is efficient yet it still has to produce the increased-targeted strategies. Besides, the results show that, the industry has caught the efficiency in compensation payments. This meets the satisfaction and expectations of the customers. Therefore, this result makes a positive contribution to the performance of the companies on the dimension of portfolio sustainability. However, the inadequacy of total premium production and the low sales channels are affecting the performance of companies negatively. Therefore, raising the quality of sales channels can lead to an increase in overall premium production, which will in turn affect the performance of the companies. It is envisaged that the increase in total premium production will also improve the profit and loss criterion by indirectly taking into account the increase in the performance of the companies and the sector. 